\title{
Oral contraceptives modify the effect of GATA3 polymorphisms on the risk of asthma at the age of 18 years via DNA methylation
}

Kranthi Guthikonda' ${ }^{1}$, Hongmei Zhang ${ }^{1}$, Vikki G Nolan ${ }^{1}$, Nelís Soto-Ramírez ${ }^{1}$, Ali H Ziyab², Susan Ewart ${ }^{5}$, Hasan S Arshad ${ }^{3,6}$, Veeresh Pati ${ }^{3,6}$, John W Holloway ${ }^{3,4}$, Gabrielle A Lockett ${ }^{4}$ and Wilfried Karmaus ${ }^{1 *}$

\begin{abstract}
Background: The prevalence of asthma in girls increases after puberty. Previous studies have detected associations between sex hormones and asthma, as well as between sex hormones and Thelper 2 (Th2) asthma-typical immune responses. Therefore, we hypothesized that exogenous or endogenous sex hormone exposure (represented by oral contraceptive pill (OCP) use and early menarche, respectively) are associated with DNA methylation (DNA-M) of the Th2 transcription factor gene, GATA3, in turn affecting the risk of asthma in girls, possibly in interaction with genetic variants.

Blood samples were collected from 245 female participants aged 18 years randomly selected for methylation analysis from the Isle of Wight birth cohort, UK. Information on use of OCPs, age at menarche, and concurrent asthma were assessed by questionnaire. Genome-wide DNA-M was determined using the Illumina Infinium HumanMethylation450 beadchip. In a first stage, we tested the interaction between sex hormone exposure and genetic variants on DNA-M of specific cytosine-phosphate-guanine (CpG) sites. In a second stage, we determined whether these $\mathrm{CpG}$ sites interact with genetic variants in GATA3 to explain the risk of asthma.

Results: Interactions between OCP use and seven single nucleotide polymorphisms (SNPs) of GATA3 were analyzed for 14 CpG sites (stage 1). The interaction between OCP use and SNP rs 1269486 was found to be associated with the methylation level of $\operatorname{cg} 17124583(P=0.002$, false discovery rate (FDR) adjusted $P=0.04)$. DNA-M of this same CpG site was also influenced by the interaction between age at menarche and rs1269486 ( $P=0.0017)$. In stage 2 , we found that cg17124583 modified the association of SNP rs422628 with asthma risk at the age of 18 years $(P=0.006$, FDR adjusted $P=0.04$ ). Subjects with genotype $A G$ showed an increase in average risk ratio (RR) from 0.31 (95\% Cl: 0.10 to 0.8 ) to 11.65 (95\% Cl: 1.71 to 79.5 ) when methylation level increased from 0.02 to 0.12 , relative to genotype $A$ A.
\end{abstract}

Conclusion: A two-stage model consisting of genetic variants in the GATA3 gene, OCP use, age at menarche, and DNA-M may explain how sex hormones in women can increase the asthma prevalence after puberty.

Keywords: GATA3 gene, DNA methylation, genetic variants, epigenetics, oral contraceptives, age at menarche, asthma, puberty, adolescence, single nucleotide polymorphism, CpG

\footnotetext{
*Correspondence: Karmaus1@memphis.edu

${ }^{1}$ Division of Epidemiology, Biostatistics, and Environmental Health, School of

Public Health, University of Memphis, Memphis, TN, USA

Full list of author information is available at the end of the article
} 


\section{Background}

Asthma is a multifactorial disease that is influenced by the interplay between genetic and environmental factors [1]. Studies have shown that the asthma prevalence in girls increases with puberty [1-4]. The mechanism behind this increase is not yet clear, though we propose that endocrine effects may be involved. In addition, asthma and lung function may vary during different phases of the menstrual cycle, further suggesting a role of sex hormones in asthma [5-7]. In addition, it has been reported that both exogenous and endogenous sex hormones influence the occurrence of asthma in young women [8].

Because estrogen and progesterone are known to decrease the contractility of airway smooth muscle, their positive correlation with asthma is more likely driven by their effects on the immune system [9]. Specifically, progesterone stimulates IL-4 production and promotes $\mathrm{T}$ helper 2 (Th2) differentiation [10]. The immunological effects of estrogen include increased production of TNF$\alpha$ by the lungs, increased production of IL- 4 by the bone marrow, and thus migration of eosinophils during allergic inflammation [11]. Furthermore, estrogen decreased expression of T-regulatory cells [12], increased expression of IL-5 and IL-13 [13], increased the differentiation of naive $\mathrm{CD}^{+}$cells into Th2 cells [13], and also increased Th2 responses by augmenting the production of dendritic cells [14]. Hence, estrogen and progesterone may be linked to potential immunological effects and variation in airway responses.

Oral contraceptive pills (OCPs) are exogenous sex hormone preparations used primarily for birth control, but also for irregular menstruation, hirsutism, polycystic ovarian disease, and dysmenorrhea. Some studies find a positive association between OCP use and asthma $[15,16]$, while other studies find the opposite relationship $[17,18]$, and yet other studies identified no significant association $[19,20]$. In addition, some studies have found early menarche to be associated with the risk of adult asthma $[8,15,16]$, while another study has reported no association $[17,18]$. Overall, there is a lack of understanding of the association between age at menarche, sex hormones, and asthma.

The transcription factor GATA3, located on chromosome 10, encodes a master regulator of Th2 cell differentiation [19] that plays an important role in the production of cytokines [20,21]. A study by Wada et al, in a mouse model of asthma, demonstrated increased production of antigen-induced Th2 cytokines in the bronchial lymph node cells of female mice compared to male mice, which was associated with enhanced GATA3 expression [2], suggesting a possible role for sex in regulating the activity of GATA3.

The term epigenetics refers to the changes in phenotype or expression of genes that are not due to changes in the sequence of DNA [22]. Epigenetics is considered to play an important role in regulation and differentiation of $\mathrm{T}$ cells and asthma pathogenesis [23,24]. In particular, DNA methylation (DNA-M) may regulate genes associated with asthma and allergy [25]. Some single nucleotide polymorphisms (SNPs) can act as methylation quantitative trait loci (methQTLs) to influence DNA-M at specific CpG sites, and may be conditional on environmental exposure [26-28]. To reflect both the genetic and environmental influences, we call these loci conditional methQTLs.

The role of sex hormones and the potential genderrelated activity of GATA3 in asthma motivated us to study a possible interaction between oral contraceptives and GATA3 and further its association with asthma. Therefore, we hypothesize that exogenous or endogenous sex hormone exposure in interaction with genetic variants could be associated with DNA-M of GATA3, which in turn affects the risk of asthma at the age of 18 years. It is also important to understand whether the change in DNA-M is a cause or a consequence of the disease. To address this issue we use a two-stage model proposed by Karmaus et al., which incorporates both methQTLs and genetic variants [29]. In stage 1, we identify the conditional methQTLs (influenced by the use of OCPs) that may result in a change of the DNA-M of specific CpG sites of the GATA3 gene. These CpG sites differentially methylated depending on OCP use subsequently may modify the penetrance of certain SNPs, which then are called modifiable genetic variants $(\operatorname{modGVs})[30,31]$. In stage 2, we evaluate the interaction of differentially methylated CpG sites with modGVs on asthma at the age of 18 years.

Age at menarche is related to changes in endogenous sex hormones and reflects body changes. In girls, the earlier the onset of puberty, the longer the exposure to sex hormones. Hence, we additionally ran our stage 1 model using age at menarche as an alternate indicator of a possible endocrine effect. Agreement between both exposures would further support our hypothesis.

\section{Results}

There were no significant differences in the prevalence of asthma, BMI, smoking at 18 years, maternal history of asthma, socioeconomic status, and median age at menarche between female offspring of the study group of this birth cohort that participated in the 18 year exam $(n=660)$ and those who were randomly selected for the DNA-M analysis $(n=245$; Table 1$)$. However, OCP missingness was different between the study group at 18 years and the 245 randomly selected girls. The difference is related to more missing information in the female study group at 18 years $(n=32,4.9 \%)$ compared to the random selection of 245 with blood samples $(n=2,0.8 \%)$. Ignoring 
Table 1 Characteristics of subjects with available methylation data compared to the female participants of the total cohort

\begin{tabular}{|c|c|c|c|}
\hline & $\begin{array}{l}\text { Total female participants, } \\
n(\%)\end{array}$ & $\begin{array}{l}\text { Female participants with DNA-M data, } \\
\qquad n(\%)\end{array}$ & $P$ value \\
\hline Factors & $n=660$ & $n=245$ & \\
\hline \multicolumn{4}{|l|}{ Maternal smoking during pregnancy } \\
\hline Yes & $159(24.1)$ & $47(19.2)$ & \\
\hline No & $498(75.5)$ & $197(80.4)$ & 0.29 \\
\hline Missing & 7 & $1(0.41)$ & \\
\hline \multicolumn{4}{|l|}{ Maternal history of asthma } \\
\hline Yes & $67(10.2)$ & $30(12.2)$ & \\
\hline No & $588(89.1)$ & $213(86.9)$ & 0.66 \\
\hline Missing & $5(0.8)$ & $2(0.82)$ & \\
\hline \multicolumn{4}{|l|}{ Asthma at 18 years } \\
\hline Yes & $128(19.4)$ & $35(14.3)$ & \\
\hline No & $531(80.5)$ & $210(85.7)$ & 0.17 \\
\hline Missing & $1(0.2)$ & 0 & \\
\hline \multicolumn{4}{|l|}{ Oral contraceptive use at 18 years } \\
\hline Yes & $293(44.4)$ & $117(47.8)$ & \\
\hline No & $335(50.7)$ & $126(51.4)$ & 0.02 \\
\hline Missing & $32(4.9)$ & $2(0.8)$ & \\
\hline \multicolumn{4}{|l|}{ Smoking at 18 years } \\
\hline Yes & $192(29.1)$ & $63(25.7)$ & \\
\hline No & $455(68.9)$ & 181(73.9) & 0.13 \\
\hline Missing & $13(2.0)$ & $1(0.4)$ & \\
\hline \multicolumn{4}{|l|}{ Socioeconomic status } \\
\hline High & $49(7.4)$ & $22(9.0)$ & \\
\hline Medium & $479(72.6)$ & $182(74.3)$ & 0.69 \\
\hline Low & $94(14.2)$ & $37(15.1)$ & \\
\hline \multirow[t]{2}{*}{ Missing } & $38(5.8)$ & $4(5.8)$ & \\
\hline & n (Median; 5\%, 95\%) & n (Median; 5\%, 95\%) & \\
\hline Body mass index at 10 years $\left(\mathrm{kg} / \mathrm{m}^{2}\right)$ & $527(17.9 ; 14.8,25.2)$ & $223(17.9 ; 15.04,25.3)$ & 0.92 \\
\hline Missing & 223 & 22 & \\
\hline Body mass index at 18 years $\left(\mathrm{kg} / \mathrm{m}^{2}\right)$ & $499(22.2 ; 18.2,32)$ & $240(22.9 ; 19.05,32.93)$ & 0.56 \\
\hline Missing & 251 & 5 & \\
\hline Age at menarche & $631(13.0 ; 11.0,15.0)$ & $233(13.0 ; 10.0,15.0)$ & 0.32 \\
\hline Missing & 119 & 12 & \\
\hline
\end{tabular}

missingness, the proportion of OCP use did not differ $(P=0.75)$. The reason for the missingness seems to be parental control at 18 years. In general, participants were interviewed separately in the study center; however, they could also mail the questionnaire or answer some questions on the phone. Fifteen of 16 girls with a mailed questionnaire did not answer the question on OCP use.

Among the female participants with methylation data, $12.2 \%$ had maternal history of asthma, 19.2\% had mothers that smoked during pregnancy, $14.3 \%$ had asthma at 18 years, $47.8 \%$ used OCPs at 18 years (44.4\% of the girls in the study group at the 18-year exam). The median age at menarche was found to be 13 years. Use of oral contraceptives and age at menarche in our sample are associated (Wilcoxon test: $P=0.001$ ); $62 \%$ of the participants with age at menarche $\leq 11$ years, $45.8 \%$ of those between 12 and 14 years, and $36 \%$ of those with $\geq 14$ years used OCPs.

Of the thirteen GATA3 SNPs that were genotyped, seven SNPs (rs1269486, rs3802604, rs3824662, rs422628, 
rs434645, rs12412241, and rs406103) were selected for further analysis since these were uncorrelated (Figure 1). Of the seven SNPs that were analyzed, rs1269486 was located in the promoter, followed by four SNPs (rs3802604, rs3824662, rs422628, and rs406103) in introns, and two SNPs (rs434645, and rs12412241) downstream of the GATA3 gene (Table 2). The mean methylation levels ( $\beta$ value) of six of the $14 \mathrm{CpG}$ sites of the GATA3 gene were low $(<0.10$; Table 3$)$, four were highly methylated (>0.90), while four CpG sites showed wider variation in methylation between individuals with mean methylation between $>0.10$ and $<0.55$.

In stage 1, after controlling for cell type composition in peripheral blood, the interaction term 'OCP use $\times$ rs1269486' was found to be associated with differential methylation of $\operatorname{cg} 17124583(P$ value $=0.002$; FDR $P$ value $=0.04$; Table 4 ), indicating that this SNP represents a conditional methQTL. OCP users with minor allele (AA) (the difference in a logit scale is -0.86; $P$ value $=0.03$ ) and heterozygous $(\mathrm{AG})$ (the difference in a logit scale is $-0.57 ; P$ value $=0.002$ ) genotypes for rs1269486 had lower average methylation than those with the major (GG) genotype. The association was adjusted for potential confounders including socioeconomic status, smoking at 18 years, and BMI at 18 years. However, none of these potential confounders changed the interaction effect by more than $10 \%$.

To replicate the OCP usage model with an alternate indicator for endocrine effects, age at menarche was investigated (Table 4). Indeed, methylation of cg17124583 was differentially methylated by the interaction of same SNP rs1269486 and age at menarche $(P=0.0017)$. In girls with the minor and heterozygous genotypes for rs1269486 methylation levels at cg17124583 were found to be higher if age at menarche was higher. The interaction was statistically significant only in those with the minor genotype (the difference in logit scale is 0.42; $P$ value $=0.003$ ). Hence, both OCP use and age at menarche in interaction with rs1269486 were associated with differential methylation of cg17124583.

Interestingly, in a small sample of 34 paired DNA-M measurements, the differentially methylated CpG site cg17124583 show some variability from 10 to 18 years (test for stability: ICC $=0.39, P=0.01$ ) with mean methylation levels of 0.06 and 0.05 , respectively. This $\mathrm{CpG}$ site shows both stability and variability, but its variance was not explained by OCP use or by age at menarche (data not shown).

In the second stage, we analyzed whether methylation of cg17124583 modifies the association between SNPs and asthma at 18 years. We tested the interaction between seven SNPs and the methylation levels of cg17124583 (differentially methylated in stage 1), and its association with asthma at 18 years. We found statistically significant interactions between the SNPs rs434645 and rs422628 with cg17124583 that modify the risk of asthma at 18 years (Table 5). For rs434645, the minor (AA) and heterozygous (AG) genotypes were combined since the direction of effect on methylation was the same for both. Then the statistical association of the interaction of cg1712583 and

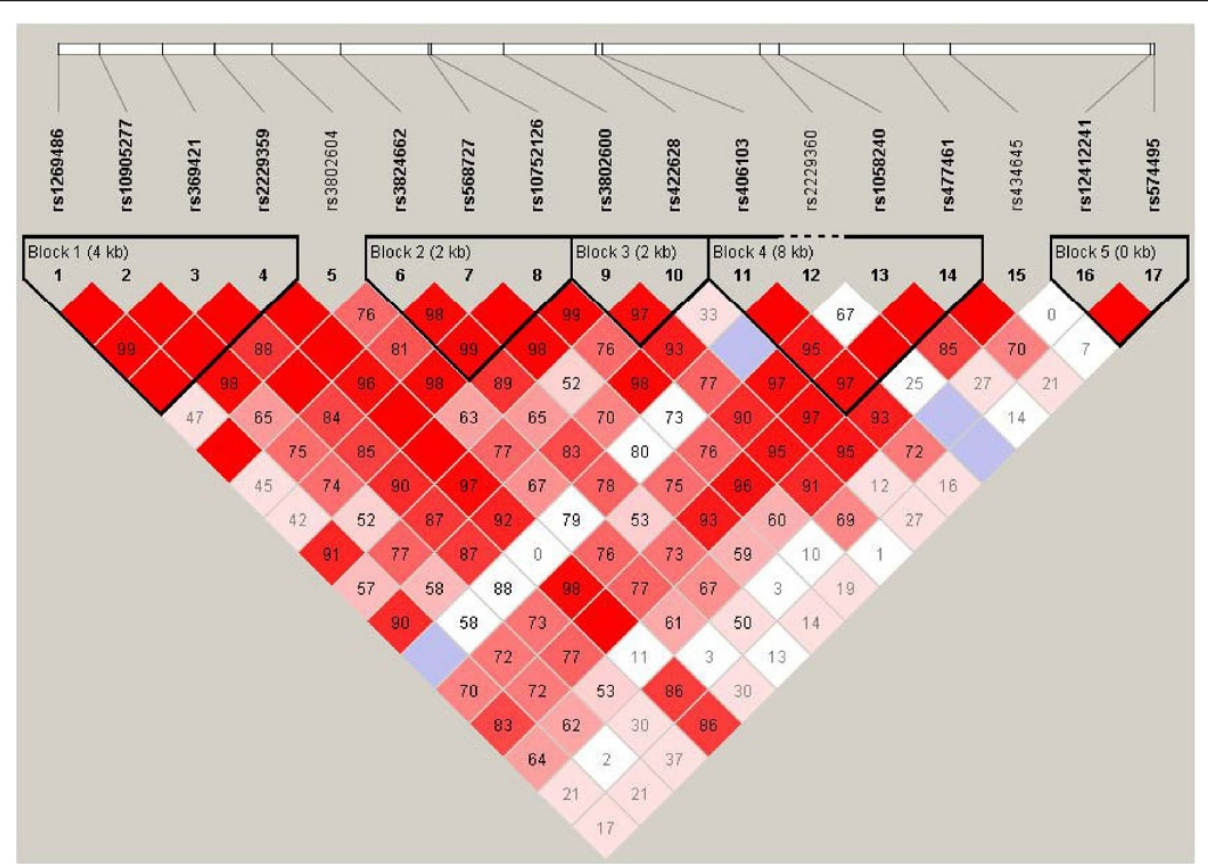

Figure 1 Linkage disequilibrium of GATA3 single nucleotide polymorphisms, standard (D'/LOD) color scheme; D' LD values displayed. 
Table 2 Single nucleotide polymorphisms (SNPs) for GATA3 and their genotypes

\begin{tabular}{|c|c|c|c|c|}
\hline SNP & Position $^{a}$ & Location & Genotype & $\begin{array}{c}\text { Frequency } \\
n(\%)\end{array}$ \\
\hline \multirow[t]{3}{*}{ rs1269486 } & 8096199 & Promoter & $\mathrm{AA}$ & $13(5.7)$ \\
\hline & & & $A G$ & 87 (37.8) \\
\hline & & & GG & $130(56.5)$ \\
\hline \multirow[t]{3}{*}{ rs3802604 } & 8102272 & Intron & $\mathrm{AA}$ & 88 (38.4) \\
\hline & & & $A G$ & $103(45.0)$ \\
\hline & & & GG & $130(56.5)$ \\
\hline \multirow[t]{3}{*}{ rs3824662 } & 8104208 & Intron & $\mathrm{AA}$ & $8(3.4)$ \\
\hline & & & $A C$ & 69 (29.6) \\
\hline & & & $\mathrm{CC}$ & $156(67.0)$ \\
\hline \multirow[t]{3}{*}{ rs422628 } & 8111409 & Intron & GG & $12(5.1)$ \\
\hline & & & $A G$ & 93 (39.9) \\
\hline & & & AA & $128(55.0)$ \\
\hline \multirow[t]{3}{*}{ rs406103 } & 8111621 & Intron (boundary) & $\mathrm{AA}$ & $13(5.6)$ \\
\hline & & & $A G$ & 78 (33.5) \\
\hline & & & GG & $142(60.9)$ \\
\hline \multirow[t]{3}{*}{ rs434645 } & 8121451 & 3'UTR & $\mathrm{AA}$ & $4(1.7)$ \\
\hline & & & $A G$ & $67(29.3)$ \\
\hline & & & GG & $158(69.0)$ \\
\hline \multirow[t]{3}{*}{ rs12412241 } & 8127139 & Downstream & $\mathrm{AA}$ & $19(8.1)$ \\
\hline & & & $A G$ & $92(39.7)$ \\
\hline & & & GG & $121(52.1)$ \\
\hline
\end{tabular}

${ }^{a}$ Nucleotide position on chromosome 10 based on build GRCh37.p13. rs434645 (AA/AG vs. GG) with asthma at 18 years was checked using the common genotype (GG) as the reference. The interaction was found to be significant $(P=$ 0.01 ; Table 5), however, it did not survive multiple testing with FDR. For the SNP rs422628, an additive genetic model was used to compare participants who had the minor (GG) and heterozygous (AG) genotypes, with those who have common (AA) genotype. The interaction term 'cg17124583 × rs422628' was found to be statistically significantly associated with asthma in those with the heterozygous genotype after adjusting for multiple comparisons $(P=0.006$; FDR adjusted $P=0.05$; Table 5$)$. The consecutive flow of assessments and its results is outlined in Figure 2. The range of DNA-M for cg17124583 was 0.01 to 0.46 . Since the number of participants at methylation levels of $<0.02$ and $>0.14$ were low, we grouped lower methylation levels into $\leq 0.02(n=4)$ and larger into $\geq 0.14$ $(n=9)$. Descriptively, 157 participants had average methylation levels of 0.05 and less at this CpG, 71 participants had 0.06 to 0.09 , and 17 participants had 0.10 to 0.46 . For subjects with AG and GG genotypes, we examined the RRs for asthma at different levels of DNA methylation. Here we present RRs for the AG genotype for the following levels: $0.02,0.04,0.06,0.08,0.10$, and 0.12 relative to subjects with AA genotype. For the AG genotype, the corresponding RRs of asthma are 0.31, 0.63, 1.31, 2.71, 5.62, and 11.65 (Figure 3). The respective 95\% CI are found in the legend of Figure 3. Figure 3 shows that the relative risk (RR) for the rs422628 AG genotype relative to AA was higher when cg17124583 was more methylated.

Table 3 Distribution of methylation on CpG sites of GATA3 gene

\begin{tabular}{|c|c|c|c|c|c|}
\hline CpG site & Location & Position & Mean methylation & $5 \%$ value & $95 \%$ value \\
\hline cg18599069 & 5'UTR & 8096991 & 0.06 & 0.04 & 0.07 \\
\hline cg10008757 & 5'UTR & 8097183 & 0.07 & 0.05 & 0.09 \\
\hline cg14327531 & 5'UTR & 8097331 & 0.06 & 0.04 & 0.08 \\
\hline cg17124583 & Body & 8097641 & 0.05 & 0.02 & 0.10 \\
\hline $\operatorname{cg} 19883813^{a}$ & Body & 8098005 & 0.04 & 0.02 & 0.08 \\
\hline cg11430077 & Body & 8099018 & 0.11 & 0.05 & 0.20 \\
\hline cg01255894 & Body & 8099218 & 0.06 & 0.03 & 0.09 \\
\hline cg10089865 & Body & 8100286 & 0.93 & 0.91 & 0.95 \\
\hline cg22770911 & Body & 8101307 & 0.52 & 0.44 & 0.60 \\
\hline cg04492228 & Body & 8101513 & 0.19 & 0.13 & 0.26 \\
\hline cg17489908 & Body & 8101566 & 0.25 & 0.17 & 0.34 \\
\hline cg03669298 & Body & 8102210 & 0.06 & 0.04 & 0.09 \\
\hline cg00463367 & Body & 8103673 & 0.20 & 0.11 & 0.31 \\
\hline cg04213746 & Body & 8106003 & 0.95 & 0.93 & 0.96 \\
\hline cg27409129 & Body & 8111731 & 0.93 & 0.92 & 0.94 \\
\hline $\operatorname{cg} 07989490^{b}$ & 3'UTR & 8117026 & 0.95 & 0.94 & 0.97 \\
\hline
\end{tabular}

${ }^{\mathrm{a}} \mathrm{CpG}$ site is not considered for further analysis because of a low methylation level $(<5 \%)$.

${ }^{b} \mathrm{CpG}$ site is not considered for further analysis because of a probe SNP. 
Table 4 Assessment of interaction of single nucleotide polymorphisms with oral contraceptive use, and with age at menarche on the methylation of the CpG site cg17124583 using linear regression $^{a^{2}}$

\begin{tabular}{|c|c|c|c|c|c|}
\hline \multirow[t]{2}{*}{ Parameter } & & \multicolumn{2}{|c|}{ Estimate (Standard error) } & \multicolumn{2}{|c|}{$P$ value } \\
\hline & & Not adjusted for cell type & Adjusted for cell type & Not adjusted for cell type & Adjusted for cell type ${ }^{a}$ \\
\hline OCP use & & $0.12(0.11)$ & $0.16(0.11)$ & 0.28 & 0.16 \\
\hline \multirow[t]{3}{*}{ rs1269486 } & AA & $0.64(0.24)$ & $0.68(0.25)$ & 0.009 & 0.006 \\
\hline & $A G$ & $0.41(0.12)$ & $042(0.13)$ & 0.001 & 0.001 \\
\hline & GG & Reference & & & \\
\hline \multirow[t]{3}{*}{ OCP use $\times$ rs1269486 } & AA & $-0.72(0.39)$ & $-0.86(0.40)$ & 0.06 & 0.03 \\
\hline & $A G$ & $-0.55(0.18)$ & $-0.57(0.18)$ & 0.002 & 0.002 \\
\hline & GG & Reference & & & \\
\hline Age at menarche & & $-0.09(0.04)$ & $-0.09(0.04)$ & 0.05 & 0.06 \\
\hline \multirow[t]{3}{*}{ rs1269486 } & AA & $-5.28(1.77)$ & $-4.87(1.78)$ & 0.003 & 0.006 \\
\hline & $A G$ & $-1.12(0.86)$ & $-1.06(0.86)$ & 0.19 & 0.21 \\
\hline & GG & Reference & & & \\
\hline \multirow[t]{3}{*}{ Age at menarche $\times$ rs 1269486} & AA & $0.45(0.14)$ & $0.42(0.14)$ & 0.001 & 0.003 \\
\hline & $A G$ & $0.09(0.06)$ & $0.09(0.06)$ & 0.14 & 0.16 \\
\hline & GG & Reference & & & \\
\hline
\end{tabular}

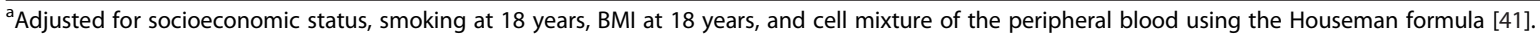

\section{Discussion}

Of the 14 CpGs and the seven SNPs that were analyzed, we identified a conditional methQTL (rs1269486) interacting with OCP usage and with age at menarche leading to a differential DNA-M of cg17124583 (Figure 2). The same differentially methylated CpG site cg17124583 in interaction with another SNP rs422628 (modGV) was found to modify the association of asthma at 18 years. This association remained statistically significant after adjusting for multiple comparisons using FDR. To our knowledge, this is the first study to identify those SNPs in the GATA3 gene that in interaction with OCP use, and with age at menarche, are associated with differential methylation of GATA3 CpG sites and consecutively with asthma.

Although the CpG site cg17124583 is located 13,768 base pairs away from rs 422628 , we can see that the risk of asthma is modulated by this CpG site. It is possible

Table 5 Log-linear models of interaction between genetic variants (rs434645 and rs422628) with DNA methylation of cg17124583 in the GATA3 gene on the prevalence of asthma at 18 years $^{\text {a }}$

\begin{tabular}{|c|c|c|c|c|}
\hline Single nucleotide and CpG site & Genotype & Estimate $^{\mathrm{b}}(\log \mathrm{RR})$ & $95 \% \mathrm{Cl}$ of $\log \mathrm{RR}$ & $P$ value \\
\hline \multicolumn{5}{|l|}{ Model for rs434645: } \\
\hline cg17124583 & & -20.31 & & \\
\hline \multirow[t]{2}{*}{ rs434645 } & $A A$ and $A G$ & -1.19 & $-2.61,0.23$ & 0.10 \\
\hline & GG & Reference & & \\
\hline \multirow[t]{2}{*}{ cg17124583 × rs434645 } & $A A$ and $A G$ & 32.77 & $7.36,58.17$ & 0.01 \\
\hline & GG & Reference & & \\
\hline \multicolumn{5}{|l|}{ Model for rs422628: } \\
\hline \multirow[t]{3}{*}{ rs422628 } & GG & -0.35 & $-3.58,2.89$ & 0.83 \\
\hline & $A G$ & -1.91 & $-3.41,-0.41$ & 0.01 \\
\hline & $\mathrm{AA}$ & Reference & & \\
\hline \multirow[t]{3}{*}{ cg17124583 x rs422628 } & GG & -8.62 & $-71.11,53.86$ & 0.79 \\
\hline & $A G$ & 36.41 & $10.67,62.14$ & 0.006 \\
\hline & AA & Reference & & \\
\hline
\end{tabular}

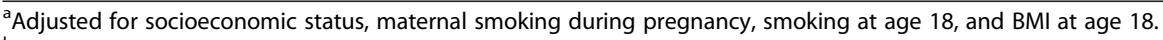

${ }^{b}$ The estimate needs to be exponentiated to calculate the risk ratio. In addition, to estimate the risk ratio due to the interaction, we need to take the two main effects and the interaction effect into account. The information is provided in Figure 3. 


\begin{tabular}{|c|c|c|}
\hline $\begin{array}{l}\text { rs1269486 } \\
\qquad X- \\
\text { endocrine } \\
\text { exposure }\end{array}$ & $\begin{array}{l}\operatorname{cg} 17124583 \\
\mathrm{rs} 422628\end{array}$ & $\begin{array}{l}\text { Asthma at } \\
\text { age } 18\end{array}$ \\
\hline $\begin{array}{l}\text { Stage } 1 \\
\text { (conditional methQTL) }\end{array}$ & $\begin{array}{l}\text { Stage } 2 \\
\text { (modGV) }\end{array}$ & \\
\hline \multicolumn{3}{|c|}{$\begin{array}{l}\text { Figure } 2 \text { Consecutive assessments of stage } 1 \text { (conditional } \\
\text { methylation quantitative trail locus) and stage } 2 \text { (modifiable } \\
\text { genetic variant) assessments. }\end{array}$} \\
\hline
\end{tabular}

that rs422628 is in linkage disequilibrium with another genetic variant, which is responsible for the functional effect on asthma risk and is adjacent to cg17124583, as has been previously observed for another gene [32].

The probability of a selection bias seems to be negligible as the study participants were randomly selected for the DNA-M analysis and for all but one variable there were no significant differences between the study population and the cohort girls who participated at 18 years. However, the proportion of missing information about the use of oral contraceptives at 18 years of age was higher in female cohort members. This was likely due to parental control, since nearly all girls whose questionnaire was mailed had missing information. We do not consider that the bias of parental control biases our results.

As the information on the use of OCPs is self-reported by the participants, there is a possibility of a misclassification. However, previous studies have shown high agreement between questionnaire data and medical records for any OCP use, current use, and time since first use [33,34]. In addition, since age at menarche is an important event in a women's life, thus, misclassifications are unlikely [35]. As the women were neither aware of their SNPs nor the methylation status, any recall bias would result in a non-differential misclassification and likely underestimate the true association. We repeated the analyses with a different exposure marker for endocrine effects, namely age at menarche, which showed a similar result. It therefore seems highly likely that the significant effects we observe on asthma risk represent an authentic link to endocrine events via differential methylation of the GATA3 gene.

The DNA-M in our study was obtained using the Illumina Infinium HumanMethylation450 beadchip array, which is demonstrated to have high validity and high reproducibility [36]. As DNA-M can be tissue-specific, it is also

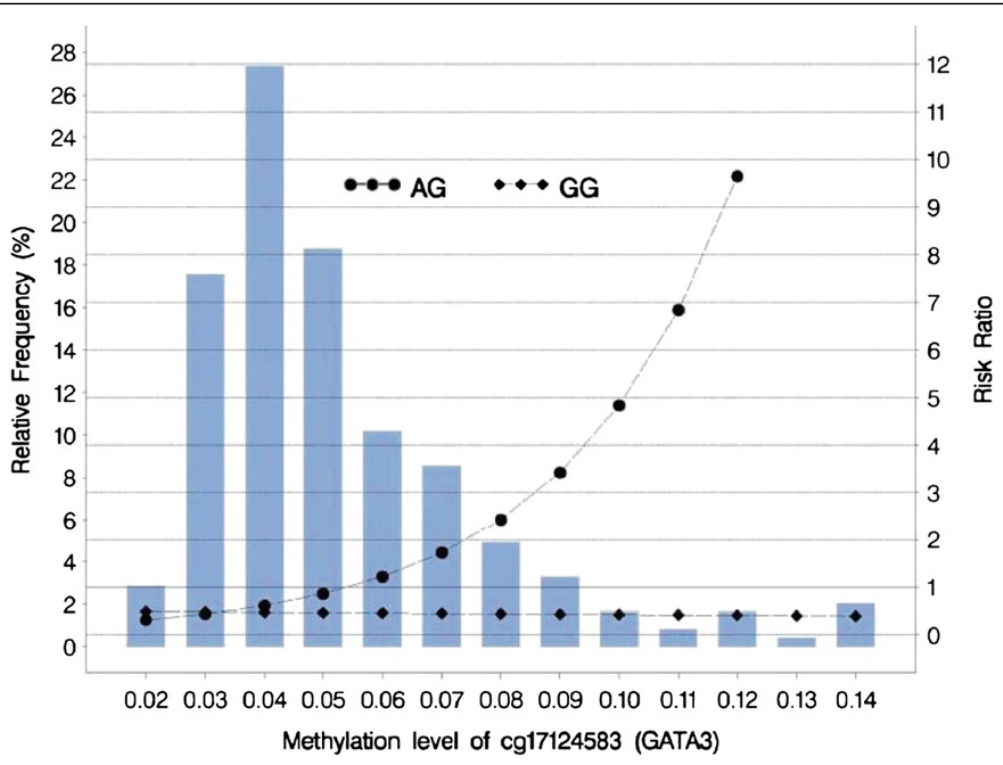

Legend

The blue bars present the relative frequency of the DNA methylation levels. For instance, $4 \%$ methylation is found in $28 \%$ of the participants. The reference genotype is AA, which is a solid horizontal line that indicates a risk ratio value of 1 . The black dot represents the AG genotype, and the diamond is the GG genotype.

\begin{tabular}{|l|c|c|c|c|c|c|c|c|c|c|c|}
\hline $\begin{array}{l}\text { Methylation } \\
\text { level (\%) }\end{array}$ & 0.02 & 0.03 & 0.04 & 0.05 & 0.06 & 0.07 & 0.08 & 0.09 & 0.10 & 0.11 & 0.12 \\
\hline $\begin{array}{l}\text { 95\% CI of the } \\
\text { risk ratio for AG }\end{array}$ & $\begin{array}{c}0.10- \\
0.89\end{array}$ & $\begin{array}{c}0.18- \\
1.09\end{array}$ & $\begin{array}{c}0.29- \\
1.38\end{array}$ & $\begin{array}{c}0.44- \\
1.89\end{array}$ & $\begin{array}{c}0.61- \\
2.82\end{array}$ & $\begin{array}{c}0.78- \\
4.54\end{array}$ & $\begin{array}{c}0.96- \\
7.71\end{array}$ & $\begin{array}{c}1.13- \\
13.52\end{array}$ & $\begin{array}{c}1.31- \\
24.16\end{array}$ & $\begin{array}{c}1.5- \\
44.66\end{array}$ & $\begin{array}{c}1.71- \\
79.5\end{array}$ \\
\hline
\end{tabular}

Figure 3 Risk ratio of asthma at 18 years versus methylation at different genotypes of GATA3 rs422628: AG and GG compared to AA [reference]. 
important to consider whether the DNA-M obtained from peripheral blood represented methylation profiles in other tissues. This issue is currently under debate [37-40]. In addition, peripheral blood leukocytes represent a mixture of cells [41]. Using CpG site information, we estimated the relative contribution of cell type composition in peripheral blood using the Houseman approach [41]. The estimated cell type composition had only a minor influence on the DNA-M of GATA3 CpG sites (Table 4), suggesting that differences in the proportions of different leukocyte do not underlie the effects reported here.

In the regression models, we observed that, although the main effects of OCP use, age at menarche, and SNPs were not significantly associated with DNA-M of cg17124583, their interactions were found to be significantly associated even after penalizing for multiple testing. Similarly, no main effects were seen for the association of OCP use, cg17124583, and the SNPs on the risk for asthma at 18 years. However, the interaction of the SNP and DNA-M were found to be statistically significant. The importance of genome-epigenome interactions in disease is increasingly recognized [42]. For example, DNA-M at the IL4R locus interacts with a local SNP to increase the RR of asthma much more dramatically than does either genotype or methylation alone [43]. Likewise DNA-M and genotype at the IL13 locus interact to influence lung function [44]. It is therefore of great importance to consider not only the disease risk imparted by the genome sequence, but how this is modified by DNA-M, which itself by be affected by environmental exposures.

Asthma being considered mainly a 'Th2 disease', we focused on the GATA3 gene because it is known to be the master regulator of Th2 cell differentiation [19] and has been linked to endocrine responses [45]. Estrogen is an immune modulator and is known to stimulate the production of Th2 cytokines, which include IL-4, IL-5, and IL-13 [11,13]. Our findings show that OCP use modifies the DNA-M of GATA3 gene. We speculate that OCPs, which contain estrogen and progesterone [46,47], may influence Th2 cytokine production via the differential methylation of GATA3 gene. Similar findings are seen with age at menarche altering the DNA-M of GATA3 gene. Statistically, although early age at menarche is related to use of OCPs, the two variables are not in complete agreement and seem to measure different features. Age at menarche is related to endogenous sex hormones [48], whereas OCPs are exogenous sex hormones. We believe that the agreement of our stage 1 findings between OCP use and age at menarche provides credence to our results. Our two-stage model suggests a potential pathway in which sex hormone-related exposures such as OCP use and age at menarche alter the DNA-M within GATA3 to subsequently affect the risk for asthma in girls at 18 years. We believe that using the two-stage model prevents reverse associations, namely that asthma initiates changes of CpG sites. In the first stage, cg17124583 was the only CpG site selected due to its relation with the interaction term of OCP use with one genetic variant (rs1269486) of the GATA3 gene and corroborated with age at menarche. Then only this CpG site was tested for an association with asthma at 18 years. However, it is not likely, but still possible that three variables (oral contraceptive use, asthma, and rs1269486) interacted in concert to influence the methylation of cg17124583.

A limitation of our study is that the RRs at methylation levels larger than $9 \%$ are only based on a limited number of individuals $(n=17)$. Another limitation is the lack of availability of the information on the type of OCP (estrogen/progesterone only pills or a combined pill), and length of time on the OCP which can further help to elucidate the role of either estrogen/progesterone or both in DNA methylation, genetic polymorphisms, and asthma.

\section{Conclusions}

This study represents the first report of an interaction of genetic variation and DNA-M of GATA3 on the risk for asthma at 18 years, which is modified by the use of OCP and age at menarche. The findings suggest a potential pathway in which OCP exposure and age at menarche, presumably via sex hormones, can alter the DNA-M of a GATA3 CpG site, which subsequently, in conjunction with genetic variants, influences the risk of asthma at 18 years. These findings provide a possible explanation for the increase in asthma prevalence in girls/women after puberty. Our results should motivate other researchers to search for interactions between genetic variants, sex hormones, and DNA-M.

\section{Methods}

\section{Study design and population}

A whole population birth cohort was established in the Isle of Wight, UK in 1989 to prospectively study the natural history and etiology of asthma and allergic conditions. The local research ethics committee (NRES Committee South Central - Hampshire B) approved the study and written informed consent was obtained from 1,456 children (January 1989 to February 1990), who were followed up at 1, 2, 4, 10, and 18 years. This Caucasian birth cohort has been described in detail elsewhere [49]. Questionnaires were completed for each child at every follow-up. Blood or saliva samples were collected at the ages of 10 and 18 years for genetic analysis.

\section{Exposures}

Information on OCP use was collected at 18 years. The question was: 'Are you on the contraceptive pill?' Age at menarche was assessed using the National Institute of 
Child and Human Development (NICHD) questionnaire from the Study of Early Child Care and Youth Development, which is based on the Pubertal Development Scale (PDS) method [50]. Among other questions on pubertal signs, the questionnaire asked: 'How old were you when you started to menstruate?'

\section{Outcome}

Asthma information was collected using the International Study of Asthma and Allergies in Childhood (ISAAC) questionnaire [51]. The questions for assessing asthma were as follows: 'History of physician diagnosed asthma?', 'Wheezing or whistling in the chest in the last 12 months?' and 'Asthma treatment in the last 12 months?' Based on the answers to these questions, asthma at 18 years was defined by physician diagnosis of asthma plus current symptoms and/or currently on asthma medication.

\section{Genotyping}

Genomic DNA was isolated from blood samples by using QIAamp DNA Blood Kits (Qiagen, Valencia, CA, USA) or the ABI PRISM 6100 Nucleic Acid PrepStation (Applied Biosystems, Foster City, CA, USA). In some cases genomic DNA was isolated from saliva using Oragene DNA Self Collection Kits (DNA Genotek, Ottawa, ON, Canada). Polymorphisms in the GATA3 gene were examined using the SNPper and Applied Biosystems databases. Genotyping was conducted by fluorogenic 5' nuclease chemistry PCR using Assays on Demands kits cycled on a 7900HT Sequence Detection System (Applied Biosystems, Foster City, CA, USA), or biotin-streptavidin-based pyrosequencing performed on PSQ-6 instrumentation (Biotage AB, Uppsala, Sweden). SNPs $(n=17)$ that tagged the GATA3 gene were identified using a tagger implemented in Haploview 4.2 using Caucasian Hapmap data, including $10 \mathrm{~kb}$ upstream and downstream of the GATA3 gene [52]. Estimates of linkage disequilibrium (LD) between SNPs were calculated using D' and $\mathrm{r}^{2}$. An $\mathrm{r}^{2}$ value of 0.85 was the threshold for tagging, and seven SNPs were selected (1 SNP from each of the 5 haplotype blocks and 2 SNPs that did not have strong linkage disequilibrium with other SNPs, Figure 1).

\section{DNA Methylation}

Stored blood samples collected at 10 and 18 years were available on the Isle of Wight, UK. For the measurement of DNA methylation at 18 years in girls, the team in the United States provided a list of 245 random identification numbers to be selected from the samples on the Isle of Wight, UK. Then for additional DNA methylation analyses of samples when these 245 women were 10 years of age, we randomly selected 34 blood samples with 16 girls with asthma and 18 girls without. DNA methylation was assessed using Illumina Infinium HumanMethylation450
BeadChips (Illumina, Inc, SanDiego, CA, USA). The 18year samples were processed in one batch. In addition, DNA methylation data were available for a sample of 34 girls at 10 years of age processed in another batch. DNA from blood samples was extracted for methylation arraying using a salting out procedure. One microgram of DNA was bisulfite-treated for cytosine to thymine conversion using the EZ 96-DNA methylation kit (Zymo Research, CA, USA), following the manufacturer's standard protocol. Arrays were processed using a standard protocol as described elsewhere [53]. The Bead Chips were scanned using a Bead Station, and the methylation level (beta $(\beta)$ value) was calculated for each queried $\mathrm{CpG}$ locus using Methylation module of GenomeStudio software.

\section{Covariates}

Maternal history of asthma and maternal smoking during pregnancy was assessed by a questionnaire administered after birth. Information about the child's active smoking status and body mass index (BMI) was collected from the 18-year questionnaire and anthropometric measurements conducted at the age of 18 years. Also assessed was 'family social status cluster', which is a composite variable derived from a combination of family income, parental occupation (socioeconomic status), and number of children in a child's bedroom [54].

In addition, since DNA methylation found in peripheral blood cells depends on cell types, we adjusted all stage 1 models for cell mixture using the method proposed by Houseman et al [41]. This method identifies CpGs within differentially methylated regions known to distinguish six types of white blood cells and then utilizes $\beta$ values at these CpGs to predict the proportions of CD8+ T-cells, CD4+ T-cells, natural killer cells, B-cells, monocytes, and granulocytes for each blood sample. The rationale to use this method for stage 1 is to estimate the change in DNA$M$ that is due to differential methylation but not due to a change in peripheral blood cell. Once we have identified such differential DNA-M, in stage 2 we are more interested in the concert of cells and their methylation level on the outcome asthma.

\section{Statistical analysis}

Preprocessing of the DNA-M data was undertaken using the IMA [55] package implemented in the $\mathrm{R}$ statistical computing package [56]. To identify tag-SNPs, LD between SNPs was calculated using D' and $r^{2}$ [57] and they were tested for Hardy-Weinberg equilibrium using Haploview 3.2 software [52]. DNA-M levels were quantified using $\beta$ values that present the proportion of methylated $(\mathrm{M})$ over the sum of methylated and unmethylated (U) allele intensities $(\beta=M /[c+M+U])$, with $c$ being a constant to prevent dividing by zero [58]. As the $\beta$ value method has severe heteroscedasticity, it is recommended 
to use M-values (logit-transformed $\beta$ values) for differential methylation analysis [59]. A logit transformation was employed for all $\beta$ values to normalize their distribution. To assess whether the subset population $(n=245)$ represents the total cohort of girls at 18 years, $x^{2}$ tests were used.

In this study, $16 \mathrm{CpG}$ sites that spanned the GATA3 gene were analyzed, out of which one $\mathrm{CpG}$ site was removed due to the presence of a probe SNP. A probe SNP is a single nucleotide polymorphism in the probe of 50 base-pairs used to determine the location of methylated CpG site. A SNP in the 50 base-pair probe may interfere with the DNA-M measurement. A second CpG site had an average methylation level $<0.05$, we removed this site from analysis as CpGs that are either very highly $(>0.95)$ or very lowly $(<0.05)$ methylated have too little variance that can be explained statistically. We added analyses on whether chip and positions had an influence on the M-values in the 245 samples. Neither chip nor positions showed significant effects or any substantial changes. In addition, in 34 female participants stability of DNA-M in blood between 10 and 18 years was estimated using intraclass correlation coefficients (ICCs).

The aim of the first stage of the two-stage model was to detect CpG sites that were affected by an interaction of SNPs and OCP usage. We ran linear regression models, in which each of the $14 \mathrm{CpG}$ sites were modeled against seven SNPs, each interacting with OCP use. Since we performed 98 tests $(14 \times 7)$ we adjusted for multiple testing by controlling the overall false discovery rate (FDR; overall FDR $=0.05$ ) [60].

Focusing on the $\mathrm{CpG}$ sites with significant interactions with OCPs, we then reran the analyses of stage 1 using age at menarche as exposure to determine if similar associations occurred with this marker of endocrine changes. If statistically significant associations are observed for both sex hormone exposures, then this strengthens the evidence that the association is related to sex hormones.

In the second stage model with asthma as the dependent variable, we used log-linear models (GENMOD procedure in SAS 9.3) to estimate statistical interactions between the methylation levels of $\mathrm{CpG}$ sites selected in stage 1 and GATA3 SNPs on the risk for asthma at age 18 years. These models included the following potential confounders: maternal history of asthma, maternal smoking during pregnancy, BMI at 18 years, smoking at 18 years, and socioeconomic status. Those confounders that changed the association of interest by $10 \%$ or more were retained as confounders in the final model. All hypotheses tested were corrected for multiple testing using the FDR. The statistical analyses were performed using the SAS statistical package (version 9.3; SAS Institute, Cary, NC, USA).

\section{Abbreviations}

BMI: Body mass index; Cl: Confidence Interval; CpG: Cytosine-phosphate-guanine dinucleotide; DNA-M: DNA methylation; FDR: False discovery rate; ICC: Intraclass correlation coefficient; ISAAC: International Study of Asthma and Allergies in Childhood; LD: Linkage disequilibrium; MethQTL: Methylation quantitative trait locus; ModGV: Modifiable genetic variant; OCP: Oral Contraceptive Pill; RR: Risk Ratio; SNP: Single nucleotide polymorphisms; Th: T helper; 5'UTR: Five prime untranslated region; 3'UTR: Three prime untranslated region.

\section{Competing interests}

The authors declare that they have no competing interests.

\section{Authors' contributions}

KG conducted the statistical analysis, interpreted the data, and drafted the manuscript. JH supervised the assessment of the DNA methylation and revised the manuscript. $\mathrm{HZ}$ directed the statistical analysis and aided in their interpretation and the final editing. SE selected and measured the single nucleotide polymorphisms and contributed to funding acquisition and the manuscript. NSR, GAL, and AHZ helped in conducting statistical analysis and editing of the manuscript. VGN aided in the interpretation of data, critical revision and final editing of the manuscript. HA and VKP were responsible for cohort assessments and asthma phenotype data and sample collection and provided critical revision and final editing of the manuscript. WK designed the study, reviewed the data quality, helped with statistical analyses, and revised the manuscript. All authors read and approved the final manuscript.

\section{Acknowledgements}

Research reported in this publication was supported by the National Institute of Allergy and Infectious Diseases under Award Number R01 Al091905-01 (PI: Wilfried Karmaus) and R01 Al061471 (PI: Susan Ewart). The 10-year follow-up of this study was funded by National Asthma Campaign, UK (Grant No 364) and the 18-year follow-up by NIH/NHLBI R01 HL082925-01 (PI: S. Hasan Arshad). The content is solely the responsibility of the authors and does not necessarily represent the official views of the National Institutes of Health. The authors gratefully acknowledge the cooperation of the children and parents who participated in this study, and appreciate the hard work of Mrs. Sharon Matthews and the Isle of Wight research team in collecting data and Nikki Graham for technical support. We thank the High-Throughput Genomics Group at the Wellcome Trust Centre for Human Genetics (funded by Wellcome Trust grant reference 090532/Z/09/Z and MRC Hub grant G0900747 91070) for the generation of the methylation data.

\section{Author details}

'Division of Epidemiology, Biostatistics, and Environmental Health, School of Public Health, University of Memphis, Memphis, TN, USA. ${ }^{2}$ Department of Epidemiology and Biostatistics, Arnold School of Public Health, University of South Carolina, Columbia, SC, USA. ${ }^{3}$ Clinical and Experimental Sciences, Faculty of Medicine, and NIHR Respiratory Biomedical Research Unit, University of Southampton, Southampton, UK. ${ }^{4}$ Human Development and Health, Faculty of Medicine, University of Southampton, Southampton, UK ${ }^{5}$ Department of Large Animal Clinical Sciences, Michigan State University, East Lansing, MI, USA. ${ }^{6}$ The David Hide Asthma and Allergy Research Centre, Isle of Wight, UK.

Received: 18 June 2014 Accepted: 10 September 2014 Published: 19 September 2014

\section{References}

1. Tollefsen $E$, Langhammer A, Romundstad P, Bjermer L, Johnsen R, Holmen $\mathrm{TL}$ : Female gender is associated with higher incidence and more stable respiratory symptoms during adolescence. Respir Med 2007, 101:896-902

2. Wada K, Okuyama K, Ohkawara Y, Takayanagi M, Ohno I: Gender differences in transcriptional regulation of IL-5 expression by bronchial lymph node cells in a mouse model of asthma. Respirology 2010, 15:629-635.

3. Soto-Ramirez N, Ziyab AH, Karmaus W, Zhang H, Kurukulaaratchy RJ, Ewart S, Arshad SH: Epidemiologic methods of assessing asthma and wheezing episodes in longitudinal studies: measures of change and stability. J Epidemiol 2013, 23:399-410.

4. Postma DS: Gender differences in asthma development and progression. Gender Medicine 2007, 4:S133-S146. 
5. Tam A, Morrish D, Wadsworth S, Dorscheid D, Man SF, Sin DD: The role of female hormones on lung function in chronic lung diseases. BMC Womens Health 2011, 11:24.

6. Siroux V, Curt F, Oryszczyn MP, Maccario J, Kauffmann F: Role of gender and hormone-related events on $\lg \mathrm{E}$, atopy, and eosinophils in the Epidemiological Study on the Genetics and Environment of Asthma, bronchial hyperresponsiveness and atopy. J Allergy Clin Immunol 2004, 114:491-498.

7. Balzano G, Fuschillo S, Melillo G, Bonini S: Asthma and sex hormones. Allergy 2001, 56:13-20.

8. Salam MT, Wenten M, Gilliland FD: Endogenous and exogenous sex steroid hormones and asthma and wheeze in young women. J Allergy Clin Immunol 2006, 117:1001-1007.

9. Haggerty $\mathrm{CL}$, Ness RB, Kelsey S, Waterer GW: The impact of estrogen and progesterone on asthma. Ann Allergy Asthma Immunol 2003, 90:284-291. quiz 291-283, 347.

10. Piccinni MP, Giudizi MG, Biagiotti R, Beloni L, Giannarini L, Sampognaro S, Parronchi P, Manetti R, Annunziato F, Livi C: Progesterone favors the development of human T helper cells producing Th2-type cytokines and promotes both IL-4 production and membrane CD30 expression in established Th1 cell clones. J Immunol 1995, 155:128-133.

11. de Oliveira AP, Domingos HV, Cavriani G, Damazo AS, Dos Santos Franco AL, Oliani SM, Oliveira-Filho RM, Vargaftig BB: Cellular recruitment and cytokine generation in a rat model of allergic lung inflammation are differentially modulated by progesterone and estradiol. Am J Physiol Cell Physiol 2007, 293:C1120-C1128.

12. Arruvito L, Sanz M, Banham AH, Fainboim L: Expansion of CD4(+)CD25(+) and FOXP3(+) regulatory T cells during the follicular phase of the menstrual cycle: Implications for human reproduction. Journal of Immunology 2007, 178:2572-2578.

13. Cai $Y$, Zhou J, Webb DC: Estrogen stimulates Th2 cytokine production and regulates the compartmentalisation of eosinophils during allergen challenge in a mouse model of asthma. Int Arch Allergy Immunol 2012, 158:252-260.

14. Uemura Y, Liu TY, Narita Y, Suzuki M, Matsushita S: 17 beta-Estradiol (E2) plus tumor necrosis factor-alpha induces a distorted maturation of human monocyte-derived dendritic cells and promotes their capacity to initiate T-helper 2 responses. Human Immunology 2008, 69:149-157.

15. Macsali F, Real FG, Plana E, Sunyer J, Anto J, Dratva J, Janson C, Jarvis D, Omenaas ER, Zemp E, Wjst M, Leynaert B, Svanes C: Early age at menarche, lung function, and adult asthma. Am J Respir Crit Care Med 2011, 183:8-14.

16. Al-Sahab B, Hamadeh MJ, Ardern Cl, Tamim H: Early Menarche Predicts Incidence of Asthma in Early Adulthood. American Journal of Epidemiology 2011, 173:S293-S293.

17. Jartti T, Saarikoski L, Jartti L, Lisinen I, Jula A, Huupponen R, Viikari J, Raitakari OT: Obesity, adipokines and asthma. Allergy 2009, 64:770-777.

18. Burgess JA, Walters EH, Byrnes GB, Giles GG, Jenkins MA, Abramson MJ, Hopper JL, Dharmage SC: Childhood adiposity predicts adult-onset current asthma in females: a 25-yr prospective study. Eur Respir J 2007 29:668-675

19. Zheng WP, Flavell RA: The transcription factor GATA-3 is necessary and sufficient for Th2 cytokine gene expression in CD4 T cells. Cell 1997 89:587-596.

20. Zhu J, Min B, Hu-Li J, Watson CJ, Grinberg A, Wang Q, Killeen N, Urban JF Jr, Guo L, Paul WE: Conditional deletion of Gata3 shows its essential function in $\mathrm{T}(\mathrm{H}) 1-\mathrm{T}(\mathrm{H}) 2$ responses. Nat Immuno/ 2004, 5:1157-1165.

21. Lee HJ, Takemoto N, Kurata H, Kamogawa Y, Miyatake S, O'Garra A, Arai N: GATA-3 induces T helper cell type 2 (Th2) cytokine expression and chromatin remodeling in committed Th1 cells. J Exp Med 2000, 192:105-115.

22. Egger $G$, Liang $G N$, Aparicio A, Jones PA: Epigenetics in human disease and prospects for epigenetic therapy. Nature 2004, 429:457-463.

23. Runyon RS, Cachola LM, Rajeshuni N, Hunter T, Garcia M, Ahn R, Lurmann F, Krasnow R, Jack LM, Miller RL, Swan GE, Kohli A, Jacobson AC, Nadeau KC: Asthma discordance in twins is linked to epigenetic modifications of $\mathrm{T}$ cells. Plos One 2012, 7:e48796.

24. Kumar RK, Hitchins MP, Foster PS: Epigenetic changes in childhood asthma. Dis Model Mech 2009, 2:549-553.

25. Kim EG, Shin HJ, Lee CG, Park HY, Kim YK, Park HW, Cho SH, Min KU, Cho ML, Park SH, Lee CW: DNA methylation and not allelic variation regulates STAT6 expression in human T cells. Clin Exp Med 2010, 10:143-152.
26. Shoemaker R, Deng J, Wang W, Zhang K: Allele-specific methylation is prevalent and is contributed by CpG-SNPs in the human genome. Genome Research 2010, 20:883-889.

27. Bell JT, Pai AA, Pickrell JK, Gaffney DJ, Pique-Regi R, Degner JF, Gilad Y, Pritchard JK: DNA methylation patterns associate with genetic and gene expression variation in HapMap cell lines. Genome Biol 2011, 12:R10.

28. Hellman A, Chess A: Extensive sequence-influenced DNA methylation polymorphism in the human genome. Epigenetics Chromatin 2010, 3:11.

29. Karmaus W, Ziyab AH, Everson T, Holloway JW: Epigenetic mechanisms and models in the origins of asthma. Curr Opin Allergy Clin Immunol 2013, 13:63-69.

30. Malousi A, Kouidou S: DNA hypermethylation of alternatively spliced and repeat sequences in humans. Molecular Genetics and Genomics 2012, 287:631-642.

31. Oberdoerffer S: A conserved role for intragenic DNA methylation in alternative pre-mRNA splicing. Transcription 2012, 3:106-109.

32. Grundberg E, Meduri E, Ling JKS, Hedman AK, Keildson S, Buil A, Busche S, Yuan W, Nisbet J, Sekowska M, Wilk A, Barrett A, Small KS, Ge B, Caron M, Shin SY, Multiple Tissue Human Expression Resource Consortium, Lathrop M, Dermitzakis ET, McCarthy MI, Spector TD, Bell JT, Deloukas P: Global analysis of DNA methylation variation in adipose tissue from twins reveals links to disease-associated variants in distal regulatory elements (vol 93, pg 876, 2013). Am J Hum Genet 2013, 93:1158-1158.

33. Bean JA, Leeper JD, Wallace RB, Sherman BM, Jagger $H$ : Variations in the reporting of menstrual histories. Am J Epidemiol 1979, 109:181-185.

34. Norell SE, Boethius G, Persson I: Oral contraceptive use: interview data versus pharmacy records. International Journal of Epidemiology 1998, 27:1033-1037.

35. Must A, Phillips SM, Naumova EN, Blum M, Harris S, Dawson-Hughes B, Rand WM: Recall of early menstrual history and menarcheal body size: After 30 years, how well do women remember? American Journal of Epidemiology 2002, 155:672-679.

36. Bibikova M, Barnes B, Tsan C, Ho V, Klotzle B, Le JM, Delano D, Zhang L, Schroth GP, Gunderson KL, Fan JB, Shen R: High density DNA methylation array with single CpG site resolution. Genomics 2011, 98:288-295.

37. Talens RPBD, Tobi EW, Kremer D, Jukema JW, Willemsen G, Putter HSP, Heijmans BT: Variation, patterns, and temporal stability of DNA methylation: considerations for epigenetic epidemiology. FASEB J 2010, 24:3135-3144

38. Terry MB, Delgado-Cruzata L, Vin-Raviv N, Wu HC, Santella RM: DNA methylation in white blood cells Association with risk factors in epidemiologic studies. Epigenetics 2011, 6:828-837.

39. Heijmans BT, Mill J: Commentary: The seven plagues of epigenetic epidemiology. International Journal of Epidemiology 2012, 41:74-78.

40. Ma B, Wilker EH, Willis-Owen SA, Byun HM, Wong KC, Motta V, Baccarelli AA, Schwartz J, Cookson WO, Khabbaz K, Mittleman MA, Moffatt MF, Liang L: Predicting DNA methylation level across human tissues. Nucleic Acids Res 2014, 42:3515-3528.

41. Houseman EA, Accomando WP, Koestler DC, Christensen BC, Marsit CJ Nelson $\mathrm{HH}$, Wiencke JK, Kelsey KT: DNA methylation arrays as surrogate measures of cell mixture distribution. BMC Bioinformatics 2012, 13:86.

42. Cooper DN, Krawczak M, Polychronakos C, Tyler-Smith C, Kehrer-Sawatzki H: Where genotype is not predictive of phenotype: towards an understanding of the molecular basis of reduced penetrance in human inherited disease. Hum Genet 2013, 132:1077-130.

43. Soto-Ramirez N, Arshad SH, Holloway J, Zhang H, Schauberger E, Ewart S, Patil V, Karmaus W: The interaction of genetic variants and DNA methylation of the interleukin-4 receptor gene increase the risk of asthma at age 18 years. Clinical Epigenetics 2013, 5:1

44. Patil VK, Holloway JW, Zhang H, Soto-Ramirez N, Ewart S, Arshad SH, Karmaus W: Interaction of prenatal maternal smoking, interleukin 13 genetic variants and DNA methylation influencing airflow and airway reactivity. Clin Epigenetics 2013, 5:22.

45. Parikh P, Palazzo JP, Rose LJ, Daskalakis C, Weigel RJ: GATA-3 expression as a predictor of hormone response in breast cancer. J Am Coll Surg 2005, 200:705-710.

46. Salem ML: Estrogen, a double-edged sword: modulation of TH1- and $\mathrm{TH} 2$-mediated inflammations by differential regulation of $\mathrm{TH} 1 / \mathrm{TH} 2$ cytokine production. Curr Drug Targets Inflamm Allergy 2004, 3:97-104.

47. Miyaura H, Iwata M: Direct and indirect inhibition of Th1 development by progesterone and glucocorticoids. Journal of Immunology 2002, 168:1087-1094 
48. Apter D, Reinila M, Vihko R: Some Endocrine Characteristics of Early Menarche, a Risk Factor for Breast-Cancer, Are Preserved into Adulthood. International Journal of Cancer 1989, 44:783-787.

49. Arshad SH, Hide DW: Effect of environmental factors on the development pf allergic disorders in infancy. J Allergy Clin Immun 1992, 90:235-241.

50. Brooks-Gunn J, Warren MP, Rosso J, Gargiulo J: Validity of self-report measures of girls' pubertal status. Child Dev 1987, 58:829-41

51. Asher Ml, Keil U, Anderson HR, Beasley R, Crane J, Martinez F, Mitchell EA, Pearce N, Sibbald B, Stewart AW, Strachan D, Weiland SK, Williams HC: International study of asthma and allergies in childhood (ISAAC): rationale and methods. Eur Respir J 1995, 8:483-491.

52. Barrett JC, Fry B, Maller J, Daly MJ: Haploview: analysis and visualization of LD and haplotype maps. Bioinformatics 2005, 21:263-265.

53. Bibikova MFJ: GoldenGate assay for DNA methylation profiling. Methods Mol Biology 2009, 507:149-163.

54. Ogbuanu IU, Karmaus W, Arshad SH, Kurukulaaratchy RJ, Ewart S: Effect of breastfeeding duration on lung function at age 10 years: a prospective birth cohort study. Thorax 2009, 64:62-66.

55. Wang DYL, Hu Q, Sucheston LE, Higgins MJ, Ambrosone CB: IMA: an R package for high-throughput analysis of Illumina's $450 \mathrm{~K}$ Infinium methylation data. Bioinformatics 2012, 28:729-730.

56. $\mathrm{R}$ : A language and environment for statistical computing. $\mathrm{R}$ Foundation for Statistical Computing. [http://www.R-project.org/]

57. Hill WG, Robertson A: The effect of linkage on limits to artificial selection (Reprinted). Genet Res 2007, 89:311-336.

58. Kuan PFWS, Zhou X, Chu H: A statistical framework for Illumina DNA methylation arrays. Bioinformatics 2010, 26:2849-2855.

59. Du P, Zhang $X$, Huang CC, Jafari N, Kibbe WA, Hou L, Lin SM: Comparison of Beta-value and M-value methods for quantifying methylation levels by microarray analysis. BMC Bioinformatics 2010, 11:587.

60. Benjamini Y, Hochberg Y: Controlling the False Discovery Rate - a Practical and Powerful Approach to Multiple Testing. J Roy Stat Soc B Met 1995, 57:289-300.

doi:10.1186/1868-7083-6-17

Cite this article as: Guthikonda et al: Oral contraceptives modify the effect of GATA3 polymorphisms on the risk of asthma at the age of 18 years via DNA methylation. Clinical Epigenetics 2014 6:17.

\section{Submit your next manuscript to BioMed Central and take full advantage of:}

- Convenient online submission

- Thorough peer review

- No space constraints or color figure charges

- Immediate publication on acceptance

- Inclusion in PubMed, CAS, Scopus and Google Scholar

- Research which is freely available for redistribution 